\title{
Community Legal Centres in the Digital Era: The Use of Digital Technologies in Queensland Community Legal Centres
}

\author{
Stebin Sam \\ Griffith University, Australia \\ Ashley Pearson \\ University of the Sunshine Coast, Australia
}

\begin{abstract}
Digital technologies are revolutionising the delivery of legal services within Australia. Challenged by innovative technologies, products and processes, the legal profession has been forced to confront their technologically disrupted future and adapt to the new technological age, as both providers and clients become progressively more reliant on increasingly sophisticated digital technology. One sector that stands to reap the benefits of digital disruption is free legal service providers, such as Community Legal Centres (CLCs), whose services benefit from the extended outreach, accessibility and efficiency that digital technologies provide. As institutions that are dedicated to ensuring that vulnerable client groups have access to justice, CLCs must be cautious not to adopt digital technologies without due thought and, consequently, potentially alienate vulnerable clients. In this new technological era, it is now more crucial than ever for CLCs to ensure that clients who may lack access to technology, are digitally illiterate, or prefer face-to-face interactions, are catered for within the CLC sector.

This paper addresses the use of technology by Queensland CLCs by drawing on data collected from semistructured, qualitative interviews with 10 employees from eight different CLCs. The article asserts that Queensland CLCs preferred to adopt digital technologies that assisted with their organisational needs over client-oriented services, attempting to strike the delicate balance between technological convenience and technological inaccessibility.
\end{abstract}

Keywords: Community legal centres; digital technology; access to justice; digital literacy.

\section{Introduction}

Digital technologies continue to revolutionise the practice of law. Presently, the legal profession is in a 'remarkable state of flux' as new technological innovations disrupt traditional legal processes. ${ }^{1}$ One sector that stands to reap the benefits of digital disruption is free legal service providers, such as Queensland's Community Legal Centres (CLCs). ${ }^{2}$ CLCs are governmentfunded organisations that provide vital legal assistance to vulnerable client groups who cannot afford the high costs of private legal representation. CLCs endeavour to ensure that all individuals - regardless of financial circumstance, disability, literacy

\footnotetext{
${ }^{1}$ Susskind, Tomorrow's Lawyers, 3-4.

${ }^{2}$ Donoghue, “The Rise of Digital Justice,” 988; Hart, “Better Justice? Or Shambolic Justice?”, 6.
}

This work is licensed under a Creative Commons Attribution 4.0 International Licence. As an open access journal, articles are free to use with proper attribution. ISSN: 2652-4074 (Online) 
skills or cultural background ${ }^{3}$ — can obtain affordable legal advice, participate in the legal system and achieve just and timely outcomes when faced with legal problems. ${ }^{4}$ In the face of increased demand for CLC services and decreased funding from government bodies, ${ }^{5}$ CLCs are moving to adopt digital technologies that enable them to be more productive and efficient in their service delivery, while also reducing costs. ${ }^{6}$

There are currently 33 CLCs in Queensland that are involved in the provision of free legal assistance, referral services, community education and law reform activities on behalf of individuals who cannot otherwise afford to pay for these services. ${ }^{7}$ The Queensland CLC sector comprises a variety of CLCs that offer different types of services and specialise in servicing different client groups. While some CLCs only provide summary legal advice via their walk-in clinics, others provide services from initial consultation to representation in litigations. ${ }^{8}$ CLCs differ from the private sector-their mission is to increase access to justice and maximise their services across the community, rather than to retain clients. ${ }^{9}$ The 2014 Productivity Commission on Access to Justice estimated that only eight per cent of Australian households are qualified for Legal Aid; however, 14 per cent of Australians live beneath the Organisation for Economic Co-operation and Development's national poverty line. ${ }^{10} \mathrm{CLCs}$ act as the safety net for individuals who do not qualify for Legal Aid, but lack the financial means to acquire private legal assistance. One study concluded that the cost-to-benefit ratio of Australian CLCs is 1:18: for every dollar the government spends on CLCs, society benefits 18 times over. ${ }^{11}$ Nevertheless, CLCs continue to face government funding restrictions, despite the Productivity Commission's recommendation to increase funding. ${ }^{12}$

The introduction of digital technologies into the legal sphere has disrupted the way that traditional legal firms operate. ${ }^{13}$ Although some legal practitioners have expressed concerns about being replaced by algorithms and artificial intelligence, ${ }^{14}$ or the unsatisfactory quality of automated work, the CLC sector welcomes the 'disruption' that digital technologies bring. Digital technologies foster new innovations that allow tech-dependent firms (such as NewLaw firms) to reimagine how legal services can be delivered. The increased technological competition in the legal sphere has also spurred more traditional and BigLaw firms to adopt technology in their practices, to remain competitive. ${ }^{15}$ In conjunction with the range of digital services offered by growing NewLaw firms, digital disruption has resulted in an overall reduction of costs for legal services across the field. ${ }^{16}$ Cost reduction and increased accessibility of legal services (via technology) are valuable to the CLC sector because these enhance access to justice for the wider population and also free up much-needed resources and time for CLCs.

Much of the global literature on technology and law has suggested that the legal profession is unwilling to embrace technological change and retains outdated methods of legal practice, despite the availability of more cost-effective and efficient technological processes and products. ${ }^{17}$ However, more recent studies have suggested that modern Queensland lawyers do not follow this trend and are, in fact, receptive to the incorporation of digital technologies into their legal practices, regardless of individual age or years since admission into legal practice. ${ }^{18}$ The delivery of legal services through technological interfaces has

\footnotetext{
${ }^{3}$ Coumarelos, Justice Made to Measure, 46; Schetzer, Access to Justice and Legal Needs, 15; Scott, Gateway to the Law, 1.

${ }^{4}$ Donoghue, "The Rise of Digital Justice," 988. Productivity Commission, Access to Justice Arrangements, 3.

${ }_{5}^{5}$ Australian Broadcasting Corporation North Queensland, "Community Legal Services Fear Cutback"; Belot, "Federal Government"; National Census of Community Legal Centres, 2016 National Report, 9. For example, in the 2016-2017 period, the Australian CLC sector faced a 30 per cent funding cut from the Commonwealth government and as a result, CLCs like Townsville's LawRight and Palm Island's Aboriginal and Torres Strait Islander Women's Legal Service nearly closed their services. Although this decision was subsequently reversed, it highlights the CLC sector's dependence on government funding.

${ }^{6}$ Donoghue, "The Rise of Digital Justice," 998; Hough, "Let’s Not Make It Worse,” 257.

${ }^{7}$ Community Legal Centres Queensland, "About Us."

${ }^{8}$ For example, Robina Community Legal Centres only provide advice during their walk-in clinics, while other centres like Environmental Defenders Office Queensland offers representation right up to litigation.

${ }^{9}$ Copeland, "Clinical Legal Education," 6.

${ }^{10}$ Australian Council of Social Service, Poverty in Australia, 46; Productivity Commission, Access to Justice Arrangements, 20.

${ }^{11}$ Storer, Economic Cost Benefit Analysis, 17.

${ }^{12}$ Productivity Commission, Access to Justice Arrangements, 703.

${ }^{13}$ Ribstein, "The Death of Big Law," 778.

${ }^{14}$ McGinnis, "The Great Disruption," 3041.

15 Guihot, "New Technology," 405-406. Michael Guihot sees disruption to the legal field as not being caused by technology; rather, disruption is a 'reaction to' client dissatisfaction. Disruption is merely a tool for enabling new solutions via technology.

${ }^{16}$ Ribstein, "The Death of Big Law," 766.

${ }^{17}$ See, for example, Jenkins, "What Can Information Technology Do For Law?”, 591; Mountain, “Could New Technologies,” 1070.

${ }^{18}$ Shum, “Are We Really Disrupted?", 34.
} 
the potential to address countless issues (e.g., connecting on the phone, securing an appointment and limited opening hours) faced by free legal service providers in traditional legal service delivery. ${ }^{19}$ However, the Queensland CLC sector appears reluctant to fully adopt digital technologies into its delivery of legal services, because the incorporation of digital technologies could create new inequalities and barriers to justice for vulnerable client groups who are unable, unwilling or otherwise not equipped to use digital technology. ${ }^{20}$

Based on qualitative research conducted with 10 Queensland CLC employees, this article asserts that the Queensland CLC sector is proactively adopting digital technologies to deliver client services and meet their organisational needs. Although the respondents envisioned a bright digital future for the CLC sector, the data illustrate that CLCs preferred to deploy digital technologies that helped to meet their organisational needs rather than replacing face-to-face client services. Throughout the study, Queensland CLC employees expressed concern that increased digital delivery of services could alienate potential clients, should they lack access to technology or the requisite digital literacy skills to take advantage of the proffered services.

\section{Methodology}

To assess the practical impact of digital technologies on Queensland CLCs, this study focused on two key research questions:

1. How are Queensland CLCs using digital technology?

2. How do Queensland CLCs see their digital future?

The study used semi-structured interviews to question 10 Queensland CLC employees about the current use of digital technologies and their speculated future applications within CLCs. Each interview lasted 30-60 minutes and occurred in a conversational manner, to allow participants the opportunity to reflect on CLCs and digital technology. ${ }^{21}$ Prompts were used to ensure that participants covered the necessary topics. ${ }^{22}$ The research obtained appropriate ethics clearance and each participant was rendered non-identifiable through the use of a unique code.

Semi-structured interviews were chosen for this study because other, similar studies have adopted similar methodologies. For example, Caroline Hart's study on the impact of government-enforced technologies on regional and rural lawyers used semistructured interviews to gather data. ${ }^{23}$ Similarly, Margaret Thornton's research on work-life balance in the legal industry used a combination of oral interviews and web-based surveys. ${ }^{24}$ Although 10 participants is not a large sample group, it has been demonstrated that eight to 10 participants is a sufficient number to conduct qualitative research and provide valuable insights into a selected research area. ${ }^{25}$

Of the10 total participants, eight were practising lawyers who either volunteered their time to assist CLC clients or were employed by CLCs, and two were involved in the management of CLCs. As is common in qualitative research, the study adopted a purposive selection methodology that sought out participants who would have a range of perspectives on the relevant topic. ${ }^{26}$ Of the 33 CLCs in Queensland, 19 were contacted regarding involvement in the study. These 19 CLCs were chosen based on the diversity of their services and locations, to garner a variety of perspectives on how digital technology is deployed in different CLCs throughout Queensland. Of the 19 CLCs contacted, 10 employees from eight CLCs agreed to be involved in the research. Two of these CLCs were from rural, regional and remote (RRR) areas and six were from metropolitan CLCs. Five of these CLCs provided general legal services, while the remaining three provided specialist legal services. We acknowledge the low number of participants and lack of diversity in CLC types as limitations of this study. The findings of this study may be further influenced by a potential self-selection bias. We acknowledge the likelihood that those who elect to participate in qualitative research studies are more likely to be interested in the topic, and hold stronger positive or negative opinions in comparison to those who did not respond to the invitation to participate; this interest may have an impact on the broader

\footnotetext{
${ }^{19}$ Mulherin, "Access to Justice and Disadvantaged Communities," 27.

${ }^{20}$ Bailey, "Access to Justice for All," 183; Denvir, "Portal or Pothole?", 678.

${ }^{21}$ Longhurst, "Semi-Structured Interviews and Focus Groups," 143.

${ }^{22}$ Harrell, Data Collection Methods, 29.

${ }^{23}$ Hart, "Better Justice? Or Shambolic Justice?", 7.

${ }^{24}$ Thornton, "The Flexible Cyborg," 4.

${ }^{25}$ Yin, Case Study Research, 55.

${ }^{26}$ Polkinghorne, "Language and Meaning,” 140; Suzuki, “The Pond You Fish In,” 298-299.
} 
conclusions and trends that are drawn out in the study findings. ${ }^{27}$ Nevertheless, this research provides a rare opportunity for meaningful discussion on the role of technology in relation to Queensland CLCs.

\section{Findings And Discussion}

The fundamental purpose of free legal service providers, such as CLCs, is to expand their services across the community so that those requiring legal assistance can easily obtain it. ${ }^{28}$ Throughout the study, participants reinforced the collective desire of CLCs to help a wide range of people; however, they also noted that insufficient time and resources often prevented all people in need from being assisted..$^{29}$ The benefits of digital technology — efficiency, speed and geographic freedom — have enabled Queensland CLCs to increase the number of people that they are able to assist. Generally, participants viewed investment in digital technology as a worthwhile use of CLC resources, as indicated by MOR28:

We do generally find that allocating resources to a particular technology that we've identified as being really useful ... is always [a] good use of money.

This section presents the findings of the study, demonstrating that the Queensland CLC sector is proactively adopting digital technology, resulting in increased effectiveness and productivity. Participants described digital technology as 'liberating' CLCs and enhancing their abilities to provide access to justice for the Queensland community by extending their delivery of legal services through the use of technology. ${ }^{30}$ The findings are presented in two sections. The first section examines the varied use of technology across Queensland CLCs. The second section outlines the preferences expressed by CLC employees to adopt technologies that meet the sector's organisational needs over client-based technologies.

\section{Use Of Digital Technology Within Queensland Community Legal Centres}

Queensland CLCs employ a range of digital technologies to meet client needs. These technologies can be classified as those used for client services and those used to meet organisational needs. Digital technologies used for client services are those that aid CLCs in corresponding with, assisting and educating clients. The sector primarily uses telephone, email, video conferencing and web-based technologies to provide client services. Digital technologies used for organisational needs are those not directly related to assisting clients, but that are nevertheless crucial for the efficient management of CLC offices. These may include practice management software, cloud-based document storage and video conferencing software. The adoption of organisational technologies may expand CLC productivity via the decentralisation of CLC offices, enabling of remote training and the automation of routine administrative tasks. Further, the time and resources that are saved by increasing productivity (through adopting organisational management software) can be redirected into assisting more clients. This section presents the findings of this study on technology use, both client-oriented and organisational, by Queensland CLCs.

\section{Digital Technologies Used For Delivering Client Services}

There exists a broad variety of digital technologies that are oriented towards delivering legal services to CLC clients and increasing access to justice. Emails and telephone calls are used by CLCs for correspondence with clients and other external parties. Video conferencing and telephone conferencing enable CLCs to deliver remote legal assistance to those who cannot attend in-office face-to-face meetings. Web-based technologies such as web homepages and social media platforms assist in making self-help material accessible and conducting community legal education.

In line with the literature, all participants agreed that telephones are a key digital technology used within the Queensland CLC sector. ${ }^{31}$ Six out of 10 participants indicated that their CLC provided legal advice over the telephone. ${ }^{32}$ One participant, HAR16, explained that telephones were considered especially useful for client recruitment because 'many [clients] have poor literacy

\footnotetext{
${ }^{27}$ Robinson, "Sampling in Interview-Based Qualitative Research,” 35-36.

${ }^{28}$ Copeland, "Clinical Legal Education," 6.

${ }^{29}$ DOR08: 'We have a certain amount of time and certain amount of funding. So, really, the idea is to help as many people as possible'; RAN05: 'I think we're doing as much as we can ... We want to do all these things but we don't have the time or the money'.

${ }^{30}$ MAR02.

${ }^{31}$ For Australian literature, see e.g., Farrell, "Queensland Community Legal Centres," 132; Queensland Association of Independent Legal Services, Queensland Community Legal Centres, 9. The considerable use of telephones is also reflected in the Canadian CLC experience; see e.g., Abramovitz, "The Role of Technology," 160.

32 Two participants, DOR08 and HAR16, made no comments on telephone appointments in their interviews.
} 
skills so the written word is not necessarily their preferred [form of] communication'. Due to significant telephone use during client recruitment, some CLCs have adopted more sophisticated telephone systems to combat the limitations of a single phone line. Prior to this change, clients often received an engaged signal due to high call volume. ${ }^{33}$ The inaccessibility of the CLC telephone helpline became a problem for one participant, CAT07: 'we actually had some people who were reluctant to refer [clients] to the service because they felt that no one could ever get through to the line'. ${ }^{34}$

Participants agreed with Carey Meyer and Kari Wrasper's characterisation of email as a primary mode of technological communication between CLC staff and clients that allows instantaneous communication and document exchange. ${ }^{35}$ GUL07 and DOR08 noted that Queensland CLCs often used emails to contact clients following the initial consultation, to take instructions, obtain documents and to send legal advice or fact sheets. ${ }^{36}$ Email was often preferred to telephone conversations due to the decreased time investment: as stated by GUL07, it is an 'unnecessary tax ... on resources to spend long hours on the phone to clients asking them questions and typing down their answers to get instructions when you can just email ... questions and let them respond in their own time'. ${ }^{37}$ Participants also found that emails replace much correspondence that was previously conducted by post. ${ }^{38}$

Video conferencing was found to be less popular than face-to-face or telephone appointments. Only four of the 10 participants had used video conferencing in client-based services. OLE12 explained that they only used video conferencing to connect with psychiatrists or interpreters, because 'usually at least one face-to-face appointment will be required' for CLC clients. ${ }^{39}$ This supports Bonnie Hough's understanding that video conferencing is best suited to connecting with external persons during faceto-face meetings with vulnerable clients, such as those with disabilities or language difficulties. ${ }^{40}$ However, in line with Suzie Forell's research, some participants were sceptical about the implementation of video conferencing within CLCs. ${ }^{41}$ One regional CLC employee, BER17, indicated that the use of video conferencing to conduct legal appointments was impractical due to inadequate internet connections, other technical difficulties and privacy concerns. The participant reported that their CLC had set up Skype facilities in several locations in remote centres to provide legal advice to people who could not access the CLC office. ${ }^{42}$ However, the program had to be discontinued due to a 'problematic' internet connection that constantly interrupted the appointments, eventually resulting in the lawyer telephoning the clients to complete the appointments. ${ }^{43}$ Skype facilities were set up in public spaces, such as the community library; therefore, BER17 suggested that clients were also concerned about privacy, due to their intimate and familiar relationships with the regional community. ${ }^{44}$ The participant explained that:

It is such a small town, so if there is an office in the library and it's got a sign on the door saying "Legal Advice Session in Progress", it makes it fairly obvious that you're getting legal advice and that decreases people's privacy and confidentiality ... Yeah, and look, the staff would be married to someone who is friends with someone you know. ${ }^{45}$

One regional CLC employee (OLE12) explained that digital technology could achieve better results in regional communities if there existed greater access to hardware or training regarding how to take advantage of the available technology:

I think if we had mini remote offices set up where someone could just pick up a laptop and Skype their lawyer or I think better training so that staff and people actually knew what technology was out there and knew how to use it [the CLC would achieve better results with regional communities]. ${ }^{46}$

\footnotetext{
${ }^{33}$ Mulherin, "Access to Justice and Disadvantaged Communities," 13, 27.

${ }^{34}$ CAT07. RAN05 also noted the same issue.

${ }^{35}$ Meyer, "E-Discovery," 949.

${ }^{36}$ GUL07; DOR08.

37 GUL07.

38 BER17.

${ }^{39}$ OLE12.

${ }^{40}$ Hough, "Let's Not Make It Worse," 262.

${ }^{41}$ Forell, "Legal Assistance by Video Conferencing," 2; BER17.

42 BER17.

${ }^{43}$ BER17.

${ }^{44}$ Giddings, "Legal Services in Rural Communities," 59.

${ }^{45}$ BER17.

${ }^{46}$ OLE12.
} 
Regional CLCs, in particular, depend on the convenience and speed of digital communication technologies to assist people in communities where there is a shortage (or a complete absence) of legal professionals, ${ }^{47}$ or where the geographic distance is so great that attending face-to-face appointments is problematic for clients. ${ }^{48}$ OLE12 explained that personalised services were crucial for remote CLCs because clients often complained about the lack of personal services delivered to them by other institutions. ${ }^{49}$ RRR clients expressed that they felt like 'second-class citizens', and were 'fatigued with feeling ignored' and 'like they don't have access to justice' ${ }^{50}$ However, the other RRR participant (BER17) added that technological interfaces such as telephone and video conferencing were the only practical way to help some people in remote communities. ${ }^{51}$ In their experience, clients were happy to receive assistance via technology because they understood that it was not viable for CLC employees to travel for face-to-face advice each week. ${ }^{52}$

Beyond direct communication with clients, Queensland CLC employees made use of web-based technologies (e.g., social media and web homepages) to provide information to people requiring legal assistance. Participants concurred that educating the community and making self-help material accessible were highly cost-effective ways to assist people with legal problems. ${ }^{53}$ CAT07 discussed the CLC sector's use of online materials to distribute information to those who may not otherwise be able to access the service:

Sometimes people might not necessarily meet all our criteria to come into the service or there might not be appointments available at that particular time, but we can refer them to the information sheets and the apps and those sorts of things and they can get some kind of assistance from us. ${ }^{54}$

Another participant, MOR28, agreed about the usefulness of online resources, explaining that clients were able to 'get most of [the] information' via fact sheets 'without having to contact [the CLC] first'. ${ }^{55}$ The redirection of clients to online resources enabled CLCs to use their limited resources to assist those clients who had specific questions that were not addressed in the fact sheet. ${ }^{56}$ MOR28 concurred that their CLC was able to help more people because online resources freed staff from needing to provide basic information to each client individually. ${ }^{57}$ In addition to fact sheets, some participants used other types of media to deliver information to the general public. HAR16 noted that they had several 'small short videos' that were accessible on their CLC website, ${ }^{58}$ and OLE12 explained that their CLC uploaded podcasts to their website to provide legal education. ${ }^{59}$ Additionally, the $24 / 7$ accessibility of online information tackled generic problems relating to traditional delivery of legal services, such as restricted business hours. ${ }^{60}$

The literature considers smartphone applications to be useful because mobile phones are the most frequently used devices for accessing online services and features. ${ }^{61}$ Many international and local Legal Aid centres and free legal service providers are creating mobile-optimised versions of their websites and smartphone applications to provide legal information. ${ }^{62}$ The literature asserts that smartphone applications are well-suited for community education and releasing self-help material; ${ }^{63}$ however, the data collected by this study suggests that mobile apps are not popular among Queensland CLCs. Only CAT07 and RAN05,

\footnotetext{
${ }^{47}$ Giddings, "Legal Services in Rural Communities," 59.

${ }^{48}$ This was the experience of BER17 and OLE12 who were both employed in regional CLCs.

${ }^{49}$ OLE12.

${ }^{50}$ OLE12.

${ }^{51}$ BER17.

${ }^{52}$ BER17.

${ }^{53}$ Copeland, "Clinical Legal Education," 8.

${ }^{54}$ CAT07.

55 MOR28.

${ }^{56}$ MOR28.

${ }^{57}$ MOR 28. The interviewer asked: 'Do you think you are able to give that one person extra help because so many others are able to help themselves?' MOR28 replied 'Yes, that's right'.

${ }^{58}$ HAR 16.

${ }^{59}$ OLE12.

${ }^{60}$ Mulherin, "Access to Justice and Disadvantaged Communities," 27.

${ }^{61}$ Australian Communication and Media Authority, The ACMA Communications Report, 3.

${ }^{62}$ Chavan, "Mobile Strategies for Legal Services," 271-274; Women's Legal Service, "Smartphone App: Re-Focus." See, for example, the Women's Legal Service Queensland's interactive application (Re-focus), which provides a variety of information for women who have separated or are thinking of separating.

${ }^{63}$ See, e.g., Dracup, "E-Learning Opportunities," 128; McKechnie, "Use of Technology by Court," 1119; Scott, "Law Online," 8; Smith,

"Telephone Hotline and Legal Advice," 4.3.
} 
who were involved with the same CLC, stated that their centre was developing mobile applications to assist clients. ${ }^{64}$ For HAR16, the practical difficulty of using smartphone applications as an information tool is that every desired change must be filtered through the app developer; 'of course, every time there is a change, everyone has to download the app again'. ${ }^{65}$

The study indicated that Queensland CLCs have a strong online and social media presence; nine out of 10 participants indicated that their CLC used one or more social media platforms and also had a website. ${ }^{66}$ Social media platforms were used 'to update clients [and] the general public ... on changes to the law', providing CLCs with a platform to present complex legal information in an alternative and informal way that may be more accessible to clients. ${ }^{67}$ However, responses were mixed regarding whether an online presence increased CLC visibility and engagement with the community. Participants CAT07 and DOR08 found that increased online activity led to more clients finding the CLC via an online platform rather than traditional methods, such as referrals. ${ }^{68}$

\begin{abstract}
We've done things on Facebook where we do like myths and facts and we share articles about things like gaslighting and we talk about things that people might not know about and then they realise oh that's actually my story, maybe I should contact these people .... we definitely get people ... messaging us saying, oh my friend is in this situation. Who should I contact? What should I do? ${ }^{69}$
\end{abstract}

However, not all participants agreed that social media increased visibility or community engagement. ${ }^{70}$ Some reported that followers on social media platforms were not necessarily clients but often other lawyers. ${ }^{71}$ One regional participant indicated that engaging in social media to post about seminars and community education programs did not increase the number of people attending the meetings. ${ }^{72}$ These experiences led GUL07 to conclude that the relationship between lawyers and clients was 'transactional'; clients engaged with CLCs in the way that 'most ordinary people engage with lawyers, when you have a problem which seems to be legal in character, you want to go get some help and advice about it so you contact a lawyer'. ${ }^{73}$ The participant did not think that clients perused a CLC website or social media pages out of interest in the CLC, but rather the client's interest 'in us [the CLC] is us helping them solve their particular problem'. ${ }^{74}$ This section has given a brief overview of the variety of digital technologies CLCs employ to meet client needs. It explored the benefits that digital technologies offer the CLC sector such as extended client outreach, accessibility of information, and efficiency of service yet acknowledged concerns that these benefits may come at the cost of vulnerable clients who are left behind in the wake of the digital revolution.

\title{
Access To Justice
}

One of the key concerns regarding the shift towards using digital technologies to deliver CLC legal services is that the adoption of such technologies may create a digital rift, denying vulnerable CLC clients much-needed access to justice. ${ }^{75}$ Study participants agreed that clients were often vulnerable people, including those from diverse and indigenous backgrounds and disadvantaged geographical locations, and those with disabilities, poor language proficiency, low levels of literacy and low income. ${ }^{76}$ Due to the vulnerable nature of such groups, Jane Bailey et al. suggest that it is less likely for these groups to possess the requisite knowledge about how to use technology, compared to the rest of society. ${ }^{77}$ Accordingly, study participants

\footnotetext{
${ }^{64}$ CAT07 and RAN05.

${ }^{65}$ HAR 16.

${ }^{66}$ The one CLC that did not have their own social media still used the social media platform of the organisation under whose auspices they worked.

${ }^{67}$ MOR28; Dracup, "E-Learning Opportunities,” 128; Ribadeneyra, "Web-based Legal Services,” 253.

${ }^{68}$ CAT07 said: 'More people are finding [the CLC] through social media and Facebook. DOR08 held similar views.

${ }^{69}$ CAT07.

${ }^{70}$ MOR28.

${ }^{71}$ DOR08.

${ }^{72}$ BER17 said 'With the information session we had on Wednesday [a legal workshop on business insolvency], we got about around 14 people there and two of them knew about that from Facebook and the rest knew about it either from the paper or word of mouth' ${ }^{72}$

${ }^{73}$ GUL07.

${ }^{74}$ GUL07.

${ }^{75}$ Hough, "Let's Not Make It Worse," 263. For example, the interviewer asked: 'Literature suggests that if you adopt too much technology, too quickly, there is a danger that you create another level of technology between those who can and those who cannot access technology?' HAR16 responded to this statement: 'That is exactly right. I would agree 100 per cent with that'.

${ }^{76}$ Coumarelos, Justice Made to Measure, 46; Schetzer, Access to Justice and Legal Needs, 20.

${ }^{77}$ Bailey, “Access to Justice for All," 183.
} 
supported digital technologies that allowed them to see more clients and rendered the CLC more productive and efficient. Conversely, they resisted technologies that jeopardised direct client contact with CLC employees, through either explicit or implicit prioritisation of certain technologies. Therefore, participants preferred to take 'small steps rather than quantum leaps ${ }^{\text {'78 }}$ in the incorporation of digital technologies; the diffusion of technologies needed to be carefully implemented and broadly accepted before a digital transition could fully take place, to ensure none are left behind. ${ }^{79}$

Some participants highlighted state-facilitated use of digital technology within the judiciary as an example of digital technology impeding rather than enhancing access to justice for vulnerable parties. SMI12 suggested that these technologies were introduced without consideration of whether 'that technology is accessible and viable and works for people'. ${ }^{80}$ BER 17 relayed an experience that followed a decision to remove the ability to download the divorce application from the court website:

[I had to] get special permission and really make a case as a community legal centre to say, hey look, not everyone is computer
literate, not everyone has a computer and some people still need to do it all by hand. ... I know there is increasing pressure
from them for everyone to move to the electronic system and I think that's really unfair ... a lot of our clients don't have a
computer. I mean, in the last session I went to there were two people [waiting with someone] because they can't read or write. ${ }^{81}$

Queensland CLC employees understood that increasing technology use may be beneficial and may save time and cost. However, participants explained that 'it is not just about [the CLC's] usability but the client's usability [of the technology]' ${ }^{82}$ For example, HAR16 explained that intending to FaceTime (video call) a client was pointless 'because the clients can't FaceTime because they don't have the data and they don't have money to pay for it on their phone' ${ }^{83}$ If CLC services are not accessible by the intended users of said services, access to justice cannot be achieved. ${ }^{84}$

CLC clients, in particular, had difficulty accessing an adequate internet connection. This includes both broadband internet and mobile data, which is the main source of internet access for clients lacking a stable home. ${ }^{85}$ Although national reports and statistics suggested that 100 per cent of Australian adults aged 18-24 years had access to the internet, experiences communicated by study participants contradicted these reports. ${ }^{86}$ Caroline Hart argued that adequate internet access is particularly problematic for clients from RRR regions. ${ }^{87}$ OLE12, a regional CLC employee, was more hopeful following the implementation of the National Broadband Network (NBN), stating:

We used to have a terrible connection out there so when Skype worked every third word would drop out or it would freeze, and it was kind of pointless and it was not great in the regional areas. NBN has just rolled out in the last couple of days $\ldots$ and that has now significantly improved. ${ }^{88}$

The digital illiteracy rates of CLC clients were also noted as a concern. ${ }^{89}$ The collected data suggested that CLCs regularly served clients who had little understanding of technology and, therefore, preferred not to receive help via digital services. DOR08 explained that, for some clients, 'computer literacy skills can be above [their] understanding'; therefore, delivering assistance solely via technological interfaces would not assist access to justice. ${ }^{90}$ Another participant indicated that it was common for them to receive handwritten affidavits from clients instead of printed or digitised copies. ${ }^{91}$ Due to such experiences with digital illiteracy, many participants agreed with the arguments of legal scholars (e.g., Lenny Abramovitz, ${ }^{92}$ Maria Karras

\footnotetext{
78 HAR16.

${ }^{79}$ Kronblad, "Beyond Digital Inventions," 142.

80 SMI12.

81 BER 17.

82 HAR 16.

83 HAR 16.

84 HAR 16.

85 HAR 16.

${ }^{86}$ Australian Communication and Media Authority, The ACMA Communications Report, 3.

${ }^{87}$ Hart, "Better Justice? Or Shambolic Justice?", 4.

88 OLE12.

${ }^{89}$ Participants that addressed this concern included BER17; OLE12; HAR16; CAT07; MOR28.

90 DOR08.

91 MOR28

92 Abramovitz, "The Role of Technology," 160.
} 
et al. ${ }^{93}$ and Wayne Moore ${ }^{94}$ ) that online self-help materials and legal assistance via technology may not be sufficient for some clients. ${ }^{95}$

This study does not assert that all CLC clients are incapable of accessing and using digital technology. For example, GUL07 noted that many of their clients could use basic technology proficiently, including accessing emails and the internet and conducting web-based searches with ease. However, individuals who lack access to technology or are digitally illiterate make up a considerable portion of CLC clients; it is these parties that may be most vulnerable during the move into the digital future.

\section{Digital Technologies Used For Organisational Needs}

Seeking to strike the delicate balance between reaping the benefits of digital accessibility and alienating clients, CLCs have been mindful in their adoption of outward, client-facing technologies. Despite such caution, the findings demonstrate that Queensland CLCs have embraced the benefits of digital technologies that address their own internal organisational needs, more willing to embrace technology when it is removed from concerns about access to justice. Technologies such as practice management software, cloud computing systems and automated data collection have increased the efficiency of administrative processes, allowing CLCs to redirect limited time and resources to assist more clients. For example, DOR08 noted that the use of Dragon Naturally Speaking (speech recognition software that transcribes notes as a person speaks) effectively eliminated the task of typing in their CLC. The removal of administrative typing duties enabled staff members to focus on other matters that were more relevant to assisting clients; this demonstrates how organisational technologies can be used to increase client access to justice. ${ }^{96}$

Most participants indicated that they used practice management software to store client details, share legal information and digitally organise the legal practice of their centre. Most of the CLCs participating in this study operated under the auspices of the National Association of Community Legal Centres; consequently, they used the mandatory practice management software - Community Legal Assistance Services System (CLASS). ${ }^{97}$ Participant experiences were in line with the Review of the National Partnership Agreement on Legal Assistance Services 2015-2020: Final Report (2018), which indicated that Queensland CLCs 'describe general satisfaction about data captured under CLASS', ${ }^{8}$ despite consensus that the implementation of CLASS has been 'fraught with issues and delays, due to an extremely limited budget and unreasonable 12 month timeframe for transition' from the previous system, Community Legal Service Information System, (CLSIS) to CLASS. ${ }^{99}$ Microsoft Office 365 was also identified by one participant as useful software that simplified administrative duties such as task allocation, organising calendar appointments, collaboration and document sharing among employees. ${ }^{100}$

Benefits of the CLASS software identified by participants included the enabling of digital intake of clients and digital storage of files relevant client cases; these could be stored via cloud, accessed remotely and easily searched. ${ }^{101}$ The CLASS software was considered by many participants to be crucial in conducting conflict-of-interest checks for new clients. As SMI12 put it, 'conflict checks is the reason to invest in [practice management software]'. ${ }^{102}$ As legal institutions involved in the provision of legal advice, CLCs are not allowed to give legal advice to two parties involved in the same matter; therefore, they must undertake a 'conflict check' for each incoming client. Due to the large number of serviced clients (up to 1100-1300 per year, according to SMI12), CLCs must follow a comprehensive process to avoid conflicts of interest. SMI12 explained that they 'can't just ask around "have we seen this person before?", so we have to have quite a rigorous process in place for doing conflict checking' ${ }^{103}$ Dependence on CLASS software was demonstrated by one participant, who explained that 'if our system was to go down for half a day it would be really problematic ... I mean you just can't have manual records where you're sort of conflict checking on names of, you know, thousands of names for the last 20 years'. ${ }^{104}$ Nevertheless, the use of practice management

\footnotetext{
${ }^{93}$ Karras, On the Edge of Justice, 146.

${ }_{94}$ Moore, The Future of Legal Aid, 4.

95 CAT07.

96 DOR08.

97 National Association of Community Legal Centres, "CLASS."

98 Urbis, "Review of the National Partnership Agreement," 94.

${ }^{99}$ Community Legal Centres Queensland Inc., "Preliminary Submission," 23.

100 SMI12.

${ }^{101}$ MAR02 found that searching the system for digitalised files using CLASS was much quicker than finding a client's physical file.

102 SMI12.

103 SMI12.

104 BER17.
} 
software to conduct conflict checks may be limited by necessary software permission. One participant discussed their difficulty in conducting conflict checks when working at an outreach clinic before the CLC was decentralised. At the time, SMI12 was unable to access the client list remotely; consequently, they had to take a copy of the entire client list on a laptop to manually conduct conflict checks when processing incoming clients. ${ }^{105}$

The digitalisation and online storage of client information and files using practice management software (e.g., CLASS) enabled CLC volunteers and managerial staff to work more freely, unrestricted by geographic location or traditional office hours. One participant, MAR02, who was employed by a decentralised CLC that operated entirely via digital technologies, explained the benefits of decentralised CLC practice:

At any one point in time there's a dozen people working on stuff - you know, from their home, from their holiday, from their office, from somewhere, and they're all working collaboratively remotely. ${ }^{106}$

Another participant, GUL07, concurred that the use of digital technologies made more efficient use of CLC employee time because employees could work from home and 'save the commute'. ${ }^{107}$ The participant also believed that the flexibility to work from home led to a better work-life balance, because they were able to be more present at home with their family. ${ }^{108}$ This assertion contradicts Margaret Thornton's research on work-life balance and digital technologies, which found that work tends to 'creep' into one's home life when work is constantly connected to you via technology. ${ }^{109}$ A few CLCs indicated that they were still using a traditional, paper-based filing system. Four participants indicated that their CLC was currently in a transitional phase between paper-based and digital systems, having not yet fully made the leap to a paperless office. ${ }^{110}$

Participants had varying degrees of success in their use of digital technologies to communicate with CLC volunteers and staff across distance. The CLCs that fully embraced the potentiality of digital technologies were reported to be more able to conduct outreach programs to remote locations and recruit more staff. For example, operating in a tech-based, decentralised CLC, two participants indicated that their CLC was now able to use remote volunteers. ${ }^{111}$ The new volunteering platform enabled potential volunteers to conduct training, provide their own practice certificates and complete induction entirely online. Upon completion, new volunteers were able to remotely volunteer for the CLC in their own free time.

However, not all participants found that technological interfaces were useful for training purposes. ${ }^{112}$ HAR 16 indicated that training and workshops often involved movement, group activities and the provision of instant feedback. In their experience, video conferencing and other web-based tools could not replicate the benefits of face-to-face meetings for conducting training; they felt that such tools were better suited for static presentations. ${ }^{113}$

SMI12's CLC had been successful in connecting their CLC's management committee via digital technology. The management committee was located all across the Gold Coast; however, SMI12 was confident that the technology was working effectively for the committee:

There are some who are down to the southern end of the coast, Coolangatta-way, right up to Southport and there's no reason to suspect that that wouldn't change to someone being near Pimpama or out in Beaudesert in the future. ${ }^{114}$

Overall, the study found a range of participant experiences relating to connecting with staff or volunteers using technology, with some experiencing success and others experiencing frustration.

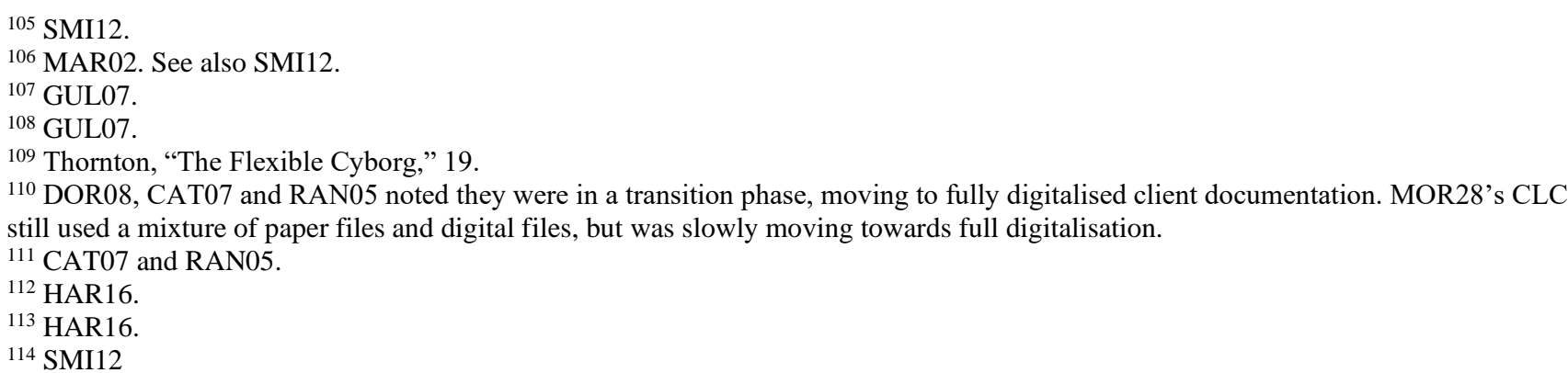


CLASS practice management software was also used by Queensland CLCs to automate the process of data collection for potential clients. The collection of data is important from a funding perspective because most funding providers require detailed empirical data on the CLC's areas of demand, the types of services they provide, the types of clients they assist and how successful their assistance is to clients. ${ }^{115}$ MAR02 identified the ability of CLASS to formulate empirical (rather than anecdotal) data on clients as one of its key strengths. ${ }^{116}$ In addition to supporting funding applications, data collection helps CLCs to understand where they ought to invest their resources. By auto-generating statistical reports, based on the information fed into the practice management system during the intake process, the system produces statistical information indicating the kinds of clients and legal problems that CLCs frequently encounter:

The more information we can get in terms of statistics about where our demand is, the better prepared [we are] to be able to handle that particular demand and the better prepared we are to go and lobby governments [for funding]. ${ }^{117}$

Without the practice management software's ability to automate data collection, participants considered the organisation of statistics to be a tedious and time-consuming process. Nevertheless, the wider CLC community has articulated concerns that the data gathered by CLASS does not accurately represent the work undertaken by CLCs at the current time, due to the newness of the software and the hurdles faced during the continuing implementation of the software across Australia. ${ }^{118}$ Overall, study participants embraced the use of technology within their local CLCs, recognising the merits of adopting digital technologies that would expedite administrative duties to allow them to spend more of their time effectively to meet client needs. ${ }^{119} \mathrm{Via}$ the use of digital technologies, CLCs are able to communicate and engage with potential volunteers and staff, regardless of location, resulting in wider availability of staff for potential clients.

In summary, digital technology forms an integral part of Queensland CLC operations, allowing CLCs to more efficiently and effectively deliver client services and meet organisational needs. The CLC sector was found to use a wide range of technology, from practice management software to cloud computing; these enabled CLCs to enhance productivity and accessibility and, consequently, to increase access to justice for clients in need of CLC services.

\section{Digital Future Of Queensland Community Legal Centres}

Regarding the second research question, about the digital future of the CLC sector, this study found that Queensland CLC employees foresaw a promising digital future for the CLC sector, in which technologies play a greater role in meeting demanding organisational needs. Unlike other areas of the global legal profession, which fear that the increased uptake in digital technology will lead to the displacement of the traditional legal firm, ${ }^{120}$ Queensland CLC employees believed that the automation of legal tasks will make the provision of broader legal assistance easier. ${ }^{121}$ Participants expressed a desire for increased adoption of digital technologies that will assist with CLC organisational needs, rather than adopting technologies that would replace face-to-face contact with clients; this is due to concerns related to accessibility, digital literacy and the need to provide personalised services.

Some participants communicated the desire for technologies that would not replace face-to-face contact directly; 'in the immediate future, at least, it will be better to see investments in technology as supporting and assisting in the automation of legal help systems rather than replacing legal help'. ${ }^{122}$ Such sentiments are in line with the literature, which has emphasised the importance of establishing rapport between clients and CLC employees through personal interactions. ${ }^{123}$ The literature demonstrates that clients deem a lawyer's trustworthiness to be more important than their technical knowledge of the law. ${ }^{124}$ Study participants from both metropolitan and RRR areas supported this evidence. OLE12, a participant from an RRR CLC, commented that:

\footnotetext{
115 BER17.

${ }^{116}$ MAR02. SMI12 also considered the empirical reporting abilities of CLASS to be useful.

117 MAR01.

118 Urbis, "Review of the National Partnership Agreement," 3, 27.

${ }^{119}$ It is acknowledged that this positive attitude towards technology may not be shared by all Queensland CLC employees and that this conclusion may be influenced by a participant self-selection bias (where applicable).

${ }^{120}$ Henderson, "Paradigm Shift."

${ }^{121}$ SMI12; GUL07; DOR08; MAR02. This assertion is also supported by the literature. See e.g., McGinnis, "The Great Disruption," 3041.

${ }^{122}$ SMI12.

${ }^{123}$ Boccaccini, "Client-Relations Skills," 110-11; Shdaimah, Negotiating Justice, 141-142.

${ }^{124}$ Boccaccini, "Client-Relations Skills," 110-11.
} 
[CLCs should use] technology to increase efficiency rather than just replace the face-to-face interactions, especially for people in rural and remote areas. When you are talking about those serious legal issues, you really want to build that rapport, know that your lawyer is on your side. ${ }^{125}$

Clients desired their lawyers to do more than simply provide the statistical probability of success in their legal matter. ${ }^{126}$ Instead, clients required lawyers with emotional intelligence, ${ }^{127}$ who could provide assurance that they understood the client's needs and recommend tailored courses of action to meet these. ${ }^{128}$ In discussing their experience of assisting clients who were experiencing highly stressful circumstances, RAN05 demonstrated the importance of establishing a personal connection:

You can have all these technologies, but they still need that face-to-face, one on one time and that's particularly relevant to our clients. Like, a client struggled to tell me her date of birth today because she was so overwhelmed, and life is so chaotic. So that means we can't just go refer her off to an app. ${ }^{129}$

Participants believed that 'the client [has] to trust the lawyer and the lawyer has to know that the client has confidence in them and that is hard to do just on the phone or through video conferencing'. ${ }^{130}$ As one participant observed, digital technology can only do what it is programmed to do:

Even with all the wonderful technology that we do have, there's a lot of things that you can't replace, you can't replace actually going and talking to someone and explaining to them and having that bit of back and forth of what's going on because, however good and however sophisticated your software architecture is, it still only does what it is programmed to do. ${ }^{131}$

For those with mental health issues or other disabilities, the use of digital technologies was considered intrusive or inaccessible. ${ }^{132}$ Due to the algorithmic nature of digital technologies, devices and the presentation of information may not accommodate client limitations or sensitivities in the way that personal interaction can.

Further, CLC employees were concerned that issues of accessibility and digital literacy would affect client ability to access legal services. One participant explained that 'as much as we can use technology, it has to always be personal not [an] impersonal type of machine interface'. ${ }^{133}$ Study participants indicated, both directly and indirectly, a preference for CLCs to adopt administrative technologies over client-based technologies. They emphasised a continued need for personalisation of legal services and the importance of accessible online resources and fact sheets.

Study participants were unconcerned about the future of disruptive technologies in the legal profession. Joseph Bower and Clayton Christensen characterise new technological innovations using two categories: disruptive and sustaining. ${ }^{134}$ Disruptive technologies are those that threaten to displace incumbent institutions by offering more expedient, automated processes or products for a lower cost. Sustaining technologies are those that maintain the current standard modes of business. This study showed that, despite receptiveness to digital technology, the Queensland CLC sector is yet to adopt more disruptive technologies (e.g., document assembly software, interactive resources, remote assistance and online learning tools) into their practices; this contrasts the way in which such technologies have been adopted by other free legal service providers in the global context. ${ }^{135}$ Rather, Queensland CLCs are adopting sustaining technologies, as is most of the international legal profession more broadly. ${ }^{136}$ Though CLCs have historically existed at the forefront of legal practice, via rebelling against conservative

125 OLE12.

${ }^{126}$ Remus, “Can Robots Be Lawyers?”, 526.

${ }^{127}$ Shdaimah, Negotiating Justice, 141-142.

${ }^{128}$ Remus, “Can Robots Be Lawyers?”, 526.

${ }^{129}$ RAN05.

${ }^{130}$ OLE12.

${ }^{131}$ SMI12.

${ }^{132}$ Karras, On the Edge of Justice, 146.

${ }^{133}$ MAR02.

${ }^{134}$ Bower, "Disruptive Technologies."

${ }^{135}$ Abramovitz, "The Role of Technology," 160; Dracup, "E-Learning Opportunities," 128; Ribadeneyra, "Web-based Legal Services," 248-252.

136 Jenkins, “What Can Information Technology Do For Law?”, 591; Mountain, “Could New Technologies,” 1066; GUL07 expressed that digital technologies were efficient but not ground-breaking and that technology can provide 'more radical opportunities' for the delivery of legal services. 
ideas of how law should be practised (e.g., using plain English, wearing casual clothes and encouraging public participation in centres), this does not appear to be reflected in their use of technology.

Participants were not apprehensive regarding the use of disruptive technologies or the potential for alternative legal service providers to enter the legal market as a result of technological growth in the legal field. ${ }^{137}$ Instead, as DOR08 argues, the introduction of less costly legal alternatives will remove some pressure from the CLC sector; 'it will make it easy for us because we will be able to refer somebody to another service ... and we can better manage our funding for the people most in need'. ${ }^{138}$ Increased technology use 'will enable one lawyer to help more people if that technology is sufficiently directed to helping those people'. ${ }^{139}$ Participants indicated that they foresaw CLCs moving to adopt more disruptive technologies, such as mobile apps (including their development) and automated document creation, in the future. ${ }^{140}$

Participants expected automation and artificial intelligence to play a greater role in the CLC sector's future. For example, SMI12 said, 'I think in the immediate future, at least, it will be better to see investments in technology as supporting and assisting in the automation of legal help systems'. ${ }^{141}$ Automation 'means that all [of the CLC's] energy can be focused on the thing you can't easily automate', such as providing personalised attention to a vulnerable client. ${ }^{142}$ DOR08 believed that automation of legal documents was soon to be a reality, stating that 'we are on the cusp of your automated electronic legal advisory databases. You can go now and type in "Letter of Demand" and you will fill in a few cues and it will give you a letter' ${ }^{143}$ GUL07 shared a similar view, indicating that many of the documents drafted for clients by the CLC were not such a 'subtle piece of work that an online app couldn't do the same thing'. ${ }^{144}$

The CLC sector saw technology as a beneficial aid in increasing individuals' ease of access to available self-help materials. Some participants believed that cloud-based systems could be used to allow both clients and the public to access pre-prepared documents. ${ }^{145}$ HAR16 advocated the use of creative media to explain legal procedures; this could be particularly useful for individuals who had 'low literacy rates and need that information presented to them in a different way so they can access it'. ${ }^{146}$ They further explained that:

I know that there are some Legal Aid resources in terms of videoing, scribing, videos where they take a legal problem and they basically have a voice over and someone scribing an animation, which is a great way to get legal information across to people in a way that is accessible and easy to understand. ${ }^{147}$

The accessibility and dissemination of self-help material were considered important because 'the courts every day are flooded with people who are self-represented because they can't afford a lawyer and they don't qualify for Legal Aid'. ${ }^{148}$ CLC employees saw a range of technologies as both assisting specific clients and providing vital information and resources to the general public, who may not be able to take advantage of CLC services.

The literature has suggested that incorporating digital technologies will enable greater future collaboration among CLCs, both on a national and international level. ${ }^{149}$ MAR02 concurred, stating:

I do think that technology has a big part to play in terms of just learning from the rest of the global village and see how they do it ... So, I think one thing I'd like to be doing a lot more of is finding out how people do that 'legal centre thing' about around the world. ${ }^{150}$

\footnotetext{
${ }^{137}$ Mountain, "Could New Technologies," 1073.

${ }^{138}$ DOR08.

${ }^{139}$ DOR08.

140 GUL07.

${ }^{141}$ SMI12.

142 SMI12.

${ }^{143}$ DOR08.

${ }^{144}$ GUL07.

${ }^{145}$ GUL07.

${ }^{146}$ HAR 16.

${ }^{147}$ HAR 16.

148 HAR 16.

${ }^{149}$ Rexer, "Overcoming Barriers," 313.

${ }^{150}$ MAR02.
} 
Some participants indicated that collective CLC knowledge could be a valuable resource to assist in both investments and decision-making. GUL07 and BER17 both explained that they occasionally conducted teleconferencing sessions with their role counterparts in other CLCs to collaboratively share ideas, knowledge and experience. ${ }^{151}$ The use of file-sharing data depositories (e.g., Dropbox) increases the potential for CLCs to collaborate, share templates and other resources, and communication tools (e.g., instant messaging and video conferencing) could help centres interact more easily, regardless of location. ${ }^{152}$

In summary, this study has demonstrated that, although disruptive innovations are not currently being used within the sector, Queensland CLC employees see digital technology playing a crucial role in the future. The sector preferred to incorporate technologies that assisted with the CLCs' organisational needs than replace face-to-face client services to ensure that CLCs remain an accessible place for vulnerable parties who are most in need of their services.

\section{Conclusion}

In the wake of digital disruption, as new digital technologies come to the fore and transform the traditional delivery of legal services, technological innovations present both opportunities and barriers for free legal providers. This study investigated the qualitative experiences of Queensland CLC volunteers and employees to explore both how digital technologies were currently being incorporated in the delivery of CLC legal practices and how CLC employees and volunteers viewed the digital future of the CLC sector. This paper demonstrated that the Queensland CLC sector was active in adopting digital technologies in their practice, which reportedly increased the sector's effectiveness and productivity. Further, this study found that Queensland CLC employees preferred the adoption of organisational digital technologies that assisted with meeting CLC administrative needs over the use of technologies that were oriented towards clients. In rationalising this preference, participants expressed multifaceted concerns about accessibility, digital literacy and the continued need to provide personalised services for vulnerable clients. In line with the literature, the results of the study demonstrated that free legal service providers are responding positively to digital disruption. The increased accessibility, efficiency and cost-effectiveness of services offered by digital technologies were identified as useful to the CLC sector. However, over-reliance on technology to provide client services was criticised for its potential to raise another barrier to access to justice for digitally illiterate or otherwise vulnerable client groups.

\section{Bibliography}

Abramovitz, Lenny. "The Role of Technology in the Provision of Poverty Law Service." Journal of Law and Social Policy, no 23 (2014): 155-163.

Australian Broadcasting Corporation North Queensland. "Community Legal Services Fear Cutback Will Impact Police, Hospital and Courts.” Australian Broadcasting Corporation, 19 April 2017. http://www.abc.net.au/news/2017-0418/community-legal-service-cuts-impact/8443736

Australian Communication and Media Authority. The ACMA Communications Report 2016-17. (Australian Communication and Media Authority, 2017).

Australian Council of Social Service. Poverty in Australia 2014 Report (Australian Council of Social Service, 2014).

Bailey, Jane, Jacquelyn Burkellet and Graham Reynolds. "Access to Justice for All: Towards an Expansive Vision of Justice and Technology." Windsor Yearbook of Access 31, no 2 (2013): 181-207.

Belot, Henry and Louise Yaxley. "Federal Government to Reverse Community Legal Funding Cuts in May Budget." Australian Broadcasting Corporation, 24 April 2017. http://www.abc.net.au/news/2017-04-24/federal-government-toreverse-community-legal-funding-cuts/8465420

Boccaccini, Marcus, Jennifer Boothby and Stanley L. Brodsky. "Client-Relations Skills in Effective Lawyering: Attitudes of Criminal Defence Attorney and Experienced Clients.” Law and Psychology Review 26, no 3 (2002): 97-121.

Bower, Joseph and Clayton Christensen. "Disruptive Technologies: Catching the Wave." Harvard Business Review 73, no 1 (1995): 43-53.

\footnotetext{
${ }^{151}$ GUL07 and BER17.

${ }^{152}$ See Queensland Association of Independent Legal Services, Queensland Community Legal Centres, 38. GUL07 also agreed that technology enabled collaboration between CLCs.
} 
Chavan, Abhijeet. "Mobile Strategies for Legal Services.” Harvard Journal of Law and Technology 26, no 1 (2012): 267278.

Community Legal Centres Queensland. “About us.” 30 April 2018. http://communitylegalqld.org.au/about-us

. Preliminary Submission to the Review of the National Partnership Agreement on Legal Assistance Services

(Community Legal Centres Queensland, 2018).

Copeland, Anna. "Clinical Legal Education within a Community Legal Centre Context." Murdoch University Electronic Journal of Law 10, no 3 (2003): 1-8.

Coumarelos, Christine, Zhigang Wei, and Albert Zhou. Justice Made to Measure: NSW Legal Needs Survey in Disadvantaged Areas (Law and Justice Foundation of New South Wales, March 2006).

Denvir, Catrina, Nigel Balmer, and Pascoe Pleasence. "Portal or Pot Hole? Exploring How Older People Use 'Information Superhighway' for Advice Relating to Problems with a Legal Dimension.” Ageing and Society 34, no 4 (2014): 670-699.

Donoghue, Jane. "The Rise of Digital Justice: Courtroom Technology, Public Participation and Access to Justice." The Modern Law Review 80, no 6 (2017): 995-1025. https://doi.org/10.1111/1468-2230.12300

Dracup, Mary and Richard Coverdale. "E-learning Opportunities and Challenges for Legal Education in Rural Victoria." Victoria Law Journal 40, no 2 (2015): 127-131. https://doi.org/10.1177\%2F1037969X1504000214

Farrell, James and Emma Philips. "Queensland Community Legal Centres Use of Information Technology to Deliver Access to Justice." Cambridge University Press 15, no 2 (2015): 131-136. https://doi.org/10.1017/S1472669615000328

Forell, Suzie, Meg Laufer, and Erol Digiusto. "Legal Assistance by Video Conferencing: What is Known?” Justice Issues 15 (2011): 1-23.

Giddings, Jeff, Barbara Hook and Jennifer Nielsen. "Legal Services in Rural Communities: Issues for Clients and Lawyers" Alternative Law Journal 26, no 2 (2001): 57-63.

Harrell, Margaret and Melissa Bradley. Data Collection Methods: Semi-structured Interviews and Focus Groups (National Defense Research Institute, 2009).

Hart, Caroline. "Better Justice? Or Shambolic Justice?: Governments' Use of Information Technology for Access to Law and Justice, and the Impact on Regional and Rural Legal Practitioners.” International Journal of Rural Law and Policy 1, no 1 (2017): 1-21.

Henderson, William and Rachel Zahorsky. "Paradigm Shift." ABA Journal 97 (2011): 40-47.

Hough, Bonnie Rose. "Let's Not Make It Worse: Issues to Consider in Adopting New Technology." Harvard Journal of Law \& Technology 26, no 1 (2012): 256-266.

Jenkins, Johnathan. "What Can Information Technology Do for Law?" Harvard Journal of Law and Technology 21, no 2 (2008): 589-607.

Karras, Maria, Emily McCarron, Abigail Gray, and Sam Ardasinski. On the Edge of Justice: The Legal Needs of People with a Mental Illness in NSW (Research Report No 4, Law and Justice Foundation of New South Wales, May 2006).

Kronblad, Charlotta and Johanna E Pregmark. "Beyond Digital Inventions: Diffusion of Technology and Organizational Capabilities to Change." In Legal Tech, Smart Contracts and Blockchain, edited by Marcelo Corrales, Mark Fenwick and Helena Haapio, 123-146. Singapore: Springer, 2015. https://doi.org/10.1007/978-981-13-6086-2

Longhurst, Robyn. "Semi-Structured Interviews and Focus Groups." In Key Methods in Geography, edited by Nicholas Clifford, Shaun French and Gill Valentine, 117-132. London: SAGE, 2017.

McGinnis, John and Russell Pearce. "The Great Disruption: How Machine Intelligence Will Transform the Role of Lawyers in the Delivery of Legal Services." Fordham Law Review 82, no 6 (2014): 3041-3066.

McKechnie, Douglas. "The Use of Technology by Court and Judiciary: Finding from a Study Stripe and Supplementary Research.” International Journal of Law and Technology 11, no 2 (2013) 1009-1148.

Meyer, Carey and Kari Wraspir. "E-Discovery: Preparing Clients for (and Protecting Them Against) Destroying in the Electronic Information Age.” William Mitchell Law Review 26, no 4 (2000): 940-966.

Moore, Wayne. The Future of Legal Aid: Systems (International Legal Aid Group, 2013).

Mountain, Darryl. “Could New Technologies Cause Great Law Firms to Fail.” Syracuse Law Review 52 (2002): $1065-1081$.

Mulherin, Geoff and Christine Coumarelos. “Access to Justice and Disadvantaged Communities." In Transforming Lives: Law and Social Process, edited by Pascoe Pleasence, Alexy Buck and Nigel Balmer, 44-66. United Kingdom: The Stationery Office, 2007.

National Association of Community Legal Centres, "CLASS." http://www.naclc.org.au/cb_pages/class.php

National Census of Community Legal Centres. 2016 National Report (National Association of Community Legal Centres, 2016).

Polkinghorne, Donald E. "Language and Meaning: Data Collection in Qualitative Research.” Journal of Counselling Psychology 52, no 2 (2005): 137-145. https://psycnet.apa.org/doi/10.1037/0022-0167.52.2.137 
Productivity Commission. Access to Justice Arrangements, Inquiry Report No. 27 (Productivity Commission, 2014). Queensland Association of Independent Legal Services. Queensland Community Legal Centres' Use of Technology

(Queensland Association of Independent Legal Services, August 2014).

Remus, Dana and Frank Levy. "Can Robots Be Lawyers? Computers, Lawyers and the Practice of Law." Georgetown Journal of Legal Ethics 30, no 3 (2017): 501-545. https://dx.doi.org/10.2139/ssrn.2701092

Rexer, Linda and Phil Malone. "Overcoming Barriers to Adoption of Effective Technology Strategies for Improving Access to Justice.” Harvard Journal of Law and Technology 26, no 1 (2012): 305-323.

Ribadeneyra, Jane. "Web-based Legal Services Delivery Capabilities.” Harvard Journal of Law and Technology 26, no 1 (2012): 246-256.

Ribstein, Larry. "The Death of Big Law.” Wisconsin Law Review, no 3 (2010): 749-815. https://dx.doi.org/10.2139/ssrn.1467730

Robinson, Oliver C. "Sampling in Interview-Based Qualitative Research: A Theoretical and Practical Guide." Qualitative Research in Psychology 11, no 1 (2014): 25-41.

Schetzer, Louis, Joanna Mullins and Roberto Buonamano. Access to Justice and Legal Needs: A Project to Identify Legal Needs, Pathways and Barriers for Disadvantaged People in NSW (Background Paper, Law and Justice Foundation of New South Wales, August 2002).

Scott, Sue. "Law Online: How Do People Access and Use Legal Information on the Internet?” Alternative Law Journal 25, no 1 (2000).

Scott, Sue and Caroline Sage. Gateway to the Law: An Exploration Study of How Non-Profit Agencies Assist Clients with Legal Problems. (Law and Justice Foundation of New South Wales, 2001).

Shdaimah, Corey. Negotiating Justice: Progressive Lawyering, Low-Income Clients and the Quest for Social Change. New York: New York University Press, 2009.

Shum, Annie and Kieran Tranter. “Are We Really Disrupted: Survey Uncovers Our Digital Mindset.” Proctor 37, no 1 (2017): 34-35.

Smith, Roger. Telephone Hotline and Legal Advice: A Preliminary Discussion Paper (International Legal Aid Group, 2013).

Storer, John, Judith Stubbs, and Colleen Lux. Economic Cost Benefit Analysis of Community Legal Centres (National Association of Community Legal Centres, June 2012).

Susskind, Richard. Tomorrow's Lawyers: An Introduction to Your Future: Second Edition. Oxford: Oxford University Press, 2017.

Suzuki, Lisa, Muninder Ahluwalia, Agnes Kwong Arora, and Jacqueline Mattis. "The Pond You Fish in Determines the Fish You Catch: Exploring Strategies for Qualitative Data Collection.” The Counselling Psychologist 35, no 2 (2007): 295327. https://doi.org/10.1177\%2F0011000006290983

Thornton, Margaret. “The Flexible Cyborg: Work-Life Balance in Legal Practice.” Sydney Law Review 38, no 1 (2016): 121.

Urbis. Review of the National Partnership Agreement on Legal Assistance Services 2015-2020: Final Report (Urbis, 2018).

Women's Legal Service, “Smartphone App: Re-Focus.” 2013. https://www.wlsq.org.au/resources/legal-toolkit/re-focus-app/

Yin, Robert. Case Study Research: Design and Methods: Fourth Edition. United States of America: SAGE, 2009. 